\title{
Tuberculosis diagnosed during pregnancy: a prospective study from London
}

\author{
Martin Llewelyn, Ian Cropley, Robert J Wilkinson, Robert N Davidson
}

\begin{abstract}
Background-A study was undertaken to characterise the presentation of tuberculosis in pregnancy and the difficulties in diagnosis in an area of the UK with a high incidence of tuberculosis.

Methods-A prospective case series was investigated at Northwick Park Hospital, a university affiliated district general hospital in Brent and Harrow health authority in north-west London which incorporates a regional infectious diseases unit. Patients diagnosed with tuberculosis over the study period were included if the onset of symptoms occurred during pregnancy. Results-Thirteen patients were diagnosed during a 30 month period from December 1995 to May 1998 during which 9069 mothers were delivered, a prevalence of 143.3/100 000 deliveries. Symptoms began at a median of 22 weeks gestation (range 9-40 weeks). All patients were recent immigrants of Indian subcontinent or Somali origin and their median duration of residence in the UK was $\mathbf{3 1}$ months (range 1-72). Prevalence broken down for racial origin of mothers was 466.3/100 000 for mothers of black African origin and 239.1/100 000 for mothers of Indian origin. Nine of the 13 patients had extrapulmonary tuberculosis. Four patients with widely disseminated disease had a negative Mantoux response and five with localised disease had a strongly positive Mantoux response. HIV co-infection was absent. The median delay between the onset of symptoms and diagnosis was seven weeks (range 2-30). The response to standard treatment was excellent and all patients were cured.
\end{abstract}

Conclusions-Tuberculosis occurring in pregnancy is common in recent immigrants. Diagnosis during pregnancy is delayed because the disease is frequently extrapulmonary with few symptoms.

(Thorax 2000;55:129-132)

Keywords: tuberculosis; pregnancy

Recent publications ${ }^{1-8}$ have described case series of tuberculosis in pregnancy within various populations, but no data have been published from the UK since $1961 .{ }^{9}$ At that time the pattern of disease in London did not differ from that seen in matched populations of young women. A similar conclusion was reached later in New York. ${ }^{10}$ Because the demographics of tuberculosis in the UK have changed considerably since 1961, this aspect of the disease needed to be reassessed.

In the light of reports from New York describing a resurgence of tuberculosis during pregnancy in association with HIV infection, ${ }^{4}$ we set out to gather prospectively a patient series to describe tuberculosis in pregnancy presenting in a British hospital where rates of tuberculosis are relatively high.

\section{Methods}

SETTING

Northwick Park is an 800 bed district general hospital which incorporates a 34 bed regional infectious diseases unit. The hospital serves a population of about 300000 in the boroughs of Brent and Harrow. The notification rate of tuberculosis in Brent in 1993 was 47.2/ 100000 population; the UK national rate was $10.1 / 100000 .^{11}$ The hospital notifies about 150 patients annually with tuberculosis. The obstetric unit performs approximately 3300 deliveries/year.

\section{SUBJECTS}

Over a 30 month period from December 1995 to May 1998 we prospectively gathered all patients with tuberculosis in whom the symptoms had started during pregnancy. Where possible the diagnosis was confirmed by culture of Mycobacterium tuberculosis or demonstration of caseating granulomas in biopsy material. Otherwise, patients were diagnosed on clinical and radiographic evidence and response to treatment. Patients were considered to have developed tuberculosis during pregnancy if the diagnosis was made during pregnancy or soon after delivery if symptoms clearly began during pregnancy. Data recorded by the midwives gave accurate figures for the total number of deliveries and the racial origins of the mothers.

\section{Results}

Thirteen patients with tuberculosis during pregnancy were documented. Details of each case including presenting features and the basis on which the diagnosis was made are given in tables 1 and 2 .

RACIAL ORIGIN OF PATIENTS

During the study period 9069 deliveries were performed, translating into an incidence of tuberculosis of 143.3/100 000 deliveries. The racial origins of the mothers were as follows: white European, 3963 (43.7\%); black African, 1930 (21.3\%); Indian, 1673 (18.4\%); black Caribbean, 416 (4.6\%); Pakistani, 346 (3.8\%); other (Bangladeshi, Mediterranean, not stated, 
Table 1 Presentation, gestation at onset of symptoms, and time to diagnosis

\begin{tabular}{|c|c|c|c|c|}
\hline Case & Site of disease & Clinical presentation & $\begin{array}{l}\text { Gestation at onset of } \\
\text { symptoms }\end{array}$ & Time to diagnosis \\
\hline 1 & Pulmonary & $\begin{array}{l}\text { Fever, weight loss. Travelled to India for } \\
\text { treatment }\end{array}$ & 4 weeks & 4 weeks \\
\hline 2 & Pulmonary & Cough and fever & 40 weeks & 8 weeks \\
\hline 3 & $\begin{array}{l}\text { Pulmonary and } \\
\text { laryngeal }\end{array}$ & Cough and fever & 3 weeks & 26 weeks \\
\hline 4 & Pulmonary & $\begin{array}{l}\text { Contact of child who had pulmonary } \\
\text { tuberculosis }\end{array}$ & Diagnosed at 30 weeks & \\
\hline 5 & $\begin{array}{l}\text { Pulmonary and } \\
\text { cerebral tuberculomas }\end{array}$ & $\begin{array}{l}\text { Seizures. History of fever and weight loss late } \\
\text { in pregnancy }\end{array}$ & 36 weeks & 17 weeks \\
\hline 6 & Pleural & Night sweats and pleural effusion & 10 weeks & 2 weeks \\
\hline 7 & Miliary & $\begin{array}{l}\text { Fever and abdominal distension. Also cough } \\
\text { and dyspnoea. Presented cachectic and } \\
\text { severely unwell }\end{array}$ & 18 weeks & 4 weeks \\
\hline 8 & Miliary & $\begin{array}{l}\text { Bell's palsy treated with steroids, developed } \\
\text { dyspnoea }\end{array}$ & 30 weeks & 4 weeks \\
\hline 9 & Miliary and TBM & Impaired cognitive state & 13 weeks & 4 weeks \\
\hline 10 & Peritoneal & $\begin{array}{l}\text { Presented with abdominal pain, distension } \\
\text { and diagnosis of possible appendicitis }\end{array}$ & 27 weeks & 6 weeks \\
\hline 11 & Ileocaecal & $\begin{array}{l}\text { Failure to gain weight in pregnancy, lower } \\
\text { abdominal pain }\end{array}$ & 16 weeks & 30 weeks \\
\hline 12 & Peritoneal & Abdominal distension and altered bowel habit & 23 weeks & 9 weeks \\
\hline 13 & Tibial osteomyelitis & Discharging sinus. Investigated after delivery & 24 weeks & 26 weeks \\
\hline
\end{tabular}

any other racial group), 741 (8.2\%). All the women in the study were born outside the UK and all were either of Somali $(n=9)$ or Indian $(\mathrm{n}=4)$ origin. They had lived in the UK a median of 31 months (range 1-72).

Although the number of Somalis among the black African mothers was not recorded, even if all these mothers were Somali this would equate to a prevalence of 466.3/100 000 deliveries for mothers of Somali origin. A total of 1673 mothers were of Indian origin, equating to a prevalence of 239.1/100 000 deliveries.

\section{SKIN RESPONSE TO TUBERCULIN}

Tuberculin testing was performed in nine patients. Anergy to tuberculin occurred in four tested patients in whom tuberculosis was disseminated and in five tested patients who had more localised disease the tuberculin response was strongly positive. All had more than $10 \mathrm{~mm}$ skin induration in response to one unit of tuberculin. As is apparent from table 2, this was frequently of diagnostic value.
HIV STATUS

Ten of the 13 patients were tested for antibodies to HIV 1 and 2. All were HIV negative. Of the three who were untested, none had risk factors for HIV infection and none had clinical features suspicious of HIV infection.

\section{CLINICAL PATTERN OF DISEASE}

Only three patients had disease confined to the lung parenchyma. Two patients presenting with respiratory disease were found on investigation to have disease elsewhere; patient 3 was found at bronchoscopy to have laryngeal tuberculomas and patient 5 had cerebral tuberculomas on CT brain scan. Three patients had disseminated miliary disease and, in total, seven had disease outside the thorax.

DURATION OF SYMPTOMS BEFORE DIAGNOSIS

In some patients there was a considerable time lapse between the onset of symptoms and a diagnosis of tuberculosis being made. Patient 1 only presented on return to the UK and patient

Table 2 Diagnosis and outcome of pregnancy

\begin{tabular}{|c|c|c|c|}
\hline Case & Site of disease & Basis of diagnosis & Outcome of pregnancy \\
\hline 1 & Pulmonary & $\begin{array}{l}\text { Positive Mantoux. Sputum smear and culture } \\
\text { positive }\end{array}$ & Therapeutic abortion at 12 weeks in India \\
\hline 2 & Pulmonary & Sputum smear and culture positive & Full term normal delivery \\
\hline 3 & Pulmonary and laryngeal & $\begin{array}{l}\text { Positive Mantoux. Bronchoscopy; laryngeal } \\
\text { tuberculomas, lavage smear and culture } \\
\text { positive }\end{array}$ & Normal delivery 38 weeks \\
\hline 4 & Pulmonary & $\begin{array}{l}\text { Chest radiographic changes. Bronchoscopy, } \\
\text { smear negative culture positive }\end{array}$ & Full term normal delivery \\
\hline 5 & $\begin{array}{l}\text { Pulmonary and cerebral } \\
\text { tuberculomas }\end{array}$ & $\begin{array}{l}\text { Positive Mantoux. Chest radiograph and CT } \\
\text { head scan appearances. Bronchoscopy; smear } \\
\text { negative culture positive }\end{array}$ & Normal delivery 36 weeks \\
\hline 6 & Pleural & $\begin{array}{l}\text { Positive Mantoux. Granulomas in pleural } \\
\text { biopsy }\end{array}$ & Full term normal delivery \\
\hline 7 & Miliary & $\begin{array}{l}\text { Miliary changes on chest radiograph. Ascitic } \\
\text { fluid culture positive }\end{array}$ & $\begin{array}{l}\text { Spontaneous abortion at } 22 \text { weeks. } 4 \text { days } \\
\text { after presentation. }\end{array}$ \\
\hline 8 & Miliary & $\begin{array}{l}\text { Miliary shadowing on chest radiograph. } \\
\text { Gastric washings culture positive }\end{array}$ & Normal delivery 37 weeks \\
\hline 9 & Miliary and TBM & $\begin{array}{l}\text { Miliary shadowing on chest radiograph. CSF } \\
\text { smear negative culture positive }\end{array}$ & Delivered at 38 weeks \\
\hline 10 & Peritoneal & $\begin{array}{l}\text { Peritoneal studding on laparotomy. Ascitic } \\
\text { fluid culture positive }\end{array}$ & Normal delivery 34 weeks \\
\hline 11 & Ileocaecal & $\begin{array}{l}\text { Characteristic barium follow through } \\
\text { changes. Response to treatment }\end{array}$ & Full term normal delivery \\
\hline 12 & Peritoneal & $\begin{array}{l}\text { Lymphocytic ascites smear negative culture } \\
\text { positive }\end{array}$ & Full term normal delivery \\
\hline 13 & Tibial osteomyelitis & $\begin{array}{l}\text { Positive Mantoux. Wound swabs smear } \\
\text { negative culture positive }\end{array}$ & Full term normal delivery \\
\hline
\end{tabular}


7 presented at an advanced stage of disease. Reasons for delay in diagnosis in the remaining 11 cases varied and are discussed below. This delay ranged from two to 30 weeks with a median of seven weeks.

\section{SENSITIVITY OF ISOLATES, TREATMENT AND} OUTCOME

All 11 isolates of Mycobacterium tuberculosis from these patients were fully sensitive to the four first line antituberculous agents (rifampicin, isoniazid, pyrazinamide and ethambutol). Patients were treated for nine or 12 months using all four of these drugs for two months and then rifampicin and isoniazid for the remaining period of treatment. Treatment was prolonged beyond the recommended six months because many of the patients had complicated disease and, in several cases, compliance was uncertain. In all patients we observed a normal response to treatment. Patient 1 chose to terminate her pregnancy abroad. Patient 7 had a spontaneous abortion at 22 weeks gestation, four days after presenting critically ill with disseminated tuberculosis.

\section{Discussion}

This is the first British series of patients developing tuberculosis in pregnancy to be reported since 1961. Unlike the earlier UK studies in which the patients were predominantly of white European descent, all our patients were recent immigrants to Britain. Most recent publications come from the developed world where the risk factors for patients developing tuberculosis were HIV co-infection or social deprivation. A few reports are from immigrant non-white populations ${ }^{378}$ but, in general, clinical data on tuberculosis in pregnancy in immigrants are lacking. This is a significant deficiency in our understanding of tuberculosis since immigration status is the major epidemiological factor in the UK. The 1993 national survey of tuberculosis in England and Wales produced incidence estimates for different ethnic groups of 4.3/100 000 for whites compared with 114.7/ 100000 and 135.2/100 000, respectively, for subjects of Indian or black African origin. ${ }^{12}$ Furthermore, there is a strong association with duration of residence in the UK. Data from the same 1993 survey show that, for adults aged 15-34 years born outside the UK, the incidence of tuberculosis after 15 years in residence was 53/100 000 compared with 440/ 100000 for immigrants resident for less than five years. ${ }^{12}$

It is of interest to consider whether the very high incidence of tuberculosis in our study reflects the background incidence in this group, or whether pregnancy is an independent risk factor for developing tuberculosis. The question of pregnancy as a risk factor for tuberculosis has been debated since the earliest days of medicine. Hippocrates believed that pregnancy had a beneficial effect on the outcome of tuberculosis and this was the view generally held until the middle of the last century. In 1850 Grissole reported a series of patients whose tuberculosis worsened during the course of their confinement. ${ }^{13}$ This view then held sway until the large case series of the $1940 / 50$ s, prior to the advent of effective antituberculosis drugs. These studies failed to show either a beneficial or detrimental effect of pregnancy on tuberculosis. ${ }^{9} 101415$ With these data the argument appeared to be settled, at least among women in developed countries. These data may not necessarily be applicable to different racial groups and studies both in the developing world and larger studies within immigrant populations such as ours are clearly indicated.

That a group of patients who, because they are pregnant, are under regular medical review can have symptoms of tuberculosis for a median of seven weeks before a diagnosis is made is clearly a cause for concern. We identified a variety of reasons for this delay. Firstly, symptoms were often non-specific - for example, lethargy, alteration in bowel habit, or failure to gain weight appropriately - and these were interpreted as usual symptoms commonly occurring in pregnancy. Secondly, the tuberculosis in these patients was commonly extrapulmonary; cough was often absent. Finally, there was an understandable tendency to defer radiological investigations during pregnancy. Useful data for comparison on duration of symptoms before diagnosis of tuberculosis are lacking in the literature. Previous studies have focused on hospitalised patients with pulmonary disease. ${ }^{16}{ }^{17}$ A recent study of 203 patients in Missouri found a median time lapse of only six days between admission and onset of treatment but information on duration of symptoms was not given. Interestingly, the delay was less for patients from ethnic minorities in this study, probably reflecting a higher index of suspicion in the attending physician. ${ }^{18}$

The lack of specific symptoms when tuberculosis occurs in pregnancy is in keeping with previous studies. Up to $20 \%$ of pregnant women with tuberculosis have been found to be asymptomatic. ${ }^{5}$ In one study a group of pregnant patients with pulmonary tuberculosis were matched to non-pregnant women with pulmonary tuberculosis and found to be significantly more likely to be asymptomatic at time of diagnosis. ${ }^{3}$ In another, pregnant patients with tuberculosis were significantly more likely to have non-specific symptoms and also to experience a delay in obtaining a chest radiograph than non-pregnant women with tuberculosis. ${ }^{7}$ Infant and maternal mortality from untreated active tuberculosis are between $30 \%$ and $40 \% .^{10} \mathrm{~A}$ recent study ${ }^{15}$ comparing outcomes in patients who started treatment early and late in pregnancy found a significant increase in obstetric morbidity and perinatal mortality in patients whose treatment was started late in pregnancy.

The high proportion of extrapulmonary tuberculosis in this series is intriguing and also partly explains the delay in diagnosis. Previous series of tuberculosis in pregnancy showed no excess of extrapulmonary disease. Ten of 16 patients in a New York study had pulmonary tuberculosis ${ }^{4}$ despite the known link between HIV infection and extrapulmonary disease. ${ }^{19}$ Nine of 10 patients in Kentucky had pulmo- 
nary tuberculosis, ${ }^{20}$ and all 27 patients whose tuberculosis occurred during pregnancy or up to one year after delivery in Denver during the late $1970 \mathrm{~s}$ had pulmonary tuberculosis. ${ }^{5}$ Twenty five patients collected over 66 months in Mexico City during the early 1990s included 12 patients with extrapulmonary disease, most of which were renal. ${ }^{8}$ In the UK, however, there is a well established link between extrapulmonary tuberculosis and immigrants. The MRC 1983 survey found $66 \%$ of immigrants from India and $63 \%$ of immigrants from Bangladesh/Pakistan to have extrapulmonary disease. ${ }^{21}$ The bias of our population towards recent immigrants may partly explain the frequency of extrapulmonary disease seen. It is interesting to note that, in the three series published from places where patients were predominantly recent immigrants or non-whites, all reported frequent extrapulmonary disease. In these reports the ratio of extrapulmonary to pulmonary cases was 2:5, 3:1, and 12:13, respectively. ${ }^{3} 78$

In New York, where the resurgence of tuberculosis was linked to HIV co-infection, the development of tuberculosis in pregnancy was similarly related to HIV. Among a total of 16 patients with tuberculosis in pregnancy over seven years, the incidence of tuberculosis increased from 12.4/100 000 deliveries between 1985 and 1990 to $94.8 / 100000$ deliveries between 1990 and 1992. Eleven of the patients were tested for HIV and seven were seropositive. The overall tuberculosis notification rate in New York in 1992 was $50.2 / 100000 .^{22}$ Although both the tuberculosis notification rate among UK immigrants and our estimates of the incidence among pregnant immigrants are much higher than the New York rates, a significant impact from HIV on tuberculosis in the UK has not been found. ${ }^{23}$

The most recent guidelines from the British Thoracic Society on control and prevention of tuberculosis make no specific recommendations regarding pregnancy. ${ }^{24}$ From our experience it is likely that pregnant women from ethnic minority groups in the UK are at an especially high risk of developing tuberculosis. Furthermore, because of the predominance of extrapulmonary disease and the non-specific symptomatology in these patients, a high index of suspicion for tuberculosis is needed when such patients develop symptoms.

The authors would like to thank Sr Margaret Logue and D Katherine Fidler for providing data on the activity of the obstetric unit during the study period.
Funding: None.

Conflict of interest: None.

1 Nolan TE, Espinosa TL, Pastorek JG 2nd. Tuberculosis skin testing in pregnancy: trends in a population. $\mathcal{F}$ Perinatol 1997;17:199-201.

2 McIntyre PB, McCormack JG, Vacca A. Tuberculosis in pregnancy: implications for antenatal screening in Australia. Med f Aust 1987;146:42-4.

3 Carter EJ, Mates S. Tuberculosis during pregnancy. The Rhode Island experience, 1987-1991. Chest 1994;106: 1466-70.

4 Margono F, Mroueh J, Garely A, et al. Resurgence of active tuberculosis among pregnant women. Obstet Gynecol 1994; 83:911-4.

5 Good J, Iseman MD, Davidson PT, et al. Tuberculosis in association with pregnancy. Am F Obstet Gynecol 1981;140: $492-8$.

6 Espinal MA, Reingold AL, Lavandera M. Effect of pregnancy on the risk of developing active tuberculosis. $\mathcal{F}$ Infect Dis 1996;173:488-91.

7 Donovan RF, Block R. Tuberculosis and pregnancy: a provincial study (1990-1996). Neth F Med 1998;52:100-6.

8 Figueroa DR, Arredondo GJL. Pregnancy and tuberculosis: influence of treatment on perinatal outcome. Am f Perinatol 1998;15:303-6.

9 Mehta BR. Pregnancy and tuberculosis. Dis Chest 1961;39: 505-10.

10 Schaefer G, Zervoudakis IA, Tucks FF, et al. Pregnancy and pulmonary tuberculosis. Obstet Gynecol 1975;46:706-15.

11 Ormerod LP, Charlett A, Gilham C, et al. Geographical distribution of tuberculosis notifications in national surveys of England and Wales in 1988 and 1993: report of the Public Health Laboratory Service/British Thoracic Society/ Health Laboratory Service/British Thoracic Society/
Department of Health Collaborative Group. Thorax 1998; 53:176-81.

12 Kumar D, Watson JM, Charlett A, et al. On behalf of the Public Health Laboratory Service/British Thoracic Society/ Department of Health Collaborative Group. Tuberculosis in England and Wales in 1993: results of a national survey. Thorax 1997;52:1060-7.

13 Grissole A. De l'influence que la grossesse et la phthsie pulmonaire excercent reciproquement l'une sur l'autre. Arch Gen Med 1850;22;41-51.

14 Cohen RC. Effect of pregnancy and parturition on pulmonary tuberculosis. BMF 1943;2:775-6.

15 Hedvall E. Pregnancy and tuberculosis. Acta Med Scand 1953;147:1-101.

16 Counsell SR, Tan JS, Dittus RS. Unsuspected pulmonary tuberculosis in a community teaching hospital. Arch Intern Med 1998;149:1274-8.

17 Mathur P, Sachs L, Auten G, et al. Delayed diagnosis of pulmonary tuberculosis in city hospitals. Arch Intern Med 1994;154:306-10

18 Rao VK, Iademarco EP, Fraser VJ, et al. Delays in the suspicion and treatment of tuberculosis among hospitalised patients. Ann Intern Med 1999;130:404-11.

19 Alpert-PL, Munsiff-SS, Gourevitch MN, et al. A prospective study of tuberculosis and human immunodeficiency virus infection: clinical manifestations and factors associated with survival. Clin Infect Dis 1997;24:661-8.

20 Wilson EA, Thelin TJ, Dilts PV. Tuberculosis complicated by pregnancy. Am $\mathcal{f}$ Obstet Gynecol 1973;115:526-9.

21 Medical Research Council Tuberculosis and Chest Diseases Unit. National survey of tuberculosis notifications in England and Wales in 1983: characteristics of disease. Tubercle 1987;68:19-32.

22 Tuberculosis, AIDS, and death among substance abusers on welfare in New York City. N Engl f Med 1996;334:828-33.

23 Nisar M, Narula M, Beeching N, et al. HIV-related tuberculosis in England and Wales. Tuberc Lung Dis 1992;73:2002.

24 Joint Tuberculosis Committee of the British Thoracic Society. Control and prevention of tuberculosis in the United Kingdom: code of practice 1994. Thorax 1994;49:1193 200 . 